\title{
EM MEIO A CHEGANÇA, CADÊ O RIO? A ETNICIDADE À MARGEM DO LUGAR
}

\author{
Emily Alves Cruz Moy \\ Universidade Estadual do Sudoeste da Bahia \\ emilymoy@hotmail.com \\ Flavia Querino da Silva \\ Universidade Estadual do Sudoeste da Bahia \\ laviaquerino4@hotmail.com \\ Ana Angélica Leal Barbosa \\ Universidade Estadual do Sudoeste da Bahia \\ aabarbosa@uesb.edu.br
}

\section{Resumo:}

O texto traça etnograficamente um percurso sócio histórico e as relações simbólicas a partir do depoimento de sujeitos nascidos no Povoado de Palmeirinha, no município de Aiquara, interior da Bahia. Tece relações à memória e etnicidade no campo onde as categorias étnicas são acionadas como marcadores de fronteiras. Interpretando numa concepção simbólica as possíveis motivações que impulsionaram o processo migratório àquela região entre o final do século XVIII, início do século XIX.

Palavras-chave: Etnicidade; Memória; Simbólico; Palmeirinha.

\begin{abstract}
:
The text traces ethnographically the sociohistorical course and symbolic relations from the testimony of people born at Povoado de Palmeirinha, in the county of Aiquara, in the interior of Bahia. Weave relationships to memory and ethnicity at the countryside, where the ethnic categories are actioned as boundary markers. Interpreting in a symbolic ideia the possible motivations that promoted the migration process to that place between the end of XVIII century and beginning of XIX century.
\end{abstract}

Keywords: Ethnicity; Memory; Symbolic; Palmeirinha. 


\section{AS FRONTEIRAS}

A etnicidade aflora suas nuances na manutenção de suas fronteiras. O contexto interétnico molda a concepção simbólica, a partir da construção de significados direcionados pelas relações entre pessoas, grupos, com o meio ambiente. O "lugar" simbólico, que também é real, é acionado quando os sujeitos fazem uso dessa categoria com demarcador cultural.

Vasculhando a memória do Sr. Urbano Limeira, hoje morador da cidade de Jequié, porém “nascido e criado em Palmeirinha”, como ele mesmo diz. Filho do Sr. Miguel Limeira da Silva e Dona Euflozina Firmina da Silva, casal chegado em Palmeirinha. Chama nossa atenção quando questionado se antes da vinda dos seus pais havia outras pessoas que já moravam em Palmeirinha, ele responde: “Ali na nossa região, lá na Palmeirinha mesmo, não”. Nós estávamos no apartamento de Sr. Urbano, em Jequié há 45 km de distância da Palmeirinha, o “ali” referido por ele, é um lugar simbólico acessado em suas lembranças. Ao mesmo tempo em que Palmeirinha é "ali" ela é também "lá", nesse movimento de aproximação e afastamento entendemos a relação dicotômico do ali/lá, onde "ali” é o lugar simbólico, a fronteira, e o "lá" o lugar geográfico. A categoria étnica é acionada quando ele diz "nossa região", o uso de "nossa" remete a um pertencimento acionado pela "região" (o lugar), mas também por um vínculo afetivo, (parentesco). Assim faz necessário contextualizar "nossa região" e o nosso povo.

A abordagem apontada por Poutignat e Streiff-Fernart (2011: p.110), e adotada aqui, é o da etnicidade como sistema cultural sob a perspectiva neoculturalista, que preconiza à atividade simbólica e "representa per se a etnicidade". Por meio das diferenças culturais, sendo o movimento nas relações humanas a condição para a negociação significados. A etnicidade sob a perspectiva de sistema simbólico, cujas categorias étnicas são símbolos, “que só possuem significações porque são definidas e utilizadas por pessoas que possuem uma compreensão e expectativas em comuns em relação às diferenças fundamentais que separam as pessoas em sua sociedade”.

Nesse tipo de abordagem os grupos étnicos não são definidos inicialmente, entretanto a etnicidade é interpretada a partir do contexto interétnico, "nos quais os atores em interação utilizam jogos de linguagem que podem ser segundo as situações, uniformes imbricados ou incomensuráveis". Esse contexto interétnico equivale na perspectiva de "concepção simbólica” proposta por Thompson (2011) como o "campo de 
interação". Onde a etnicidade é acessada na forma de significar. O símbolo como propõe Sodré (2005: p.36), "é, um operador de estrutura, um agenciador de vazios, de formas sem significados atuais, uma vez que a 'significação' é a própria regra de organização, a regra sintática, o valor constituinte de uma linguagem, que introduz o indivíduo na ordem coletiva".

O sentido de coletividade dado à memória, não se trata de um sentido material, como também o sentido de etnicidade dado a um grupo. No plano da subjetividade, Halbwachs (1990: p.27) encontra justificativas que "para confirmar ou recordar uma lembrança indivíduos presentes sob uma forma material e sensível, não são necessárias". Nem sempre a relação entre "eu" e o "outro" acontece no sentido estrito físico, mas também no campo do pensamento, da imaginação, pois a concepção do ponto de vista do "eu" é impulsionado e construído pelos ideais do “outro", que mesmo não presentes atuam na constituição de memória, seriam a construção do ponto de vista do "eu" influenciado sob a perspectiva do "outro". Logo, a coletividade nem sempre está associado à memória de indivíduos do mesmo grupo social, nem do mesmo plano físico - expandindo assim à ancestralidade. É nesse mesmo campo dicotómico que a etnicidade é acionada, e as fronteiras são instituídas. As fronteiras são simbólicas. São determinadas em situações sociais de interação. O “nosso lugar” que o Sr. Urbano fala, é constituído por todos que já se foram, os que estão, e os que virão. É o lugar onde as coisas acontecem.

\section{O NOSSO LUGAR}

Na Bahia ao se percorrer a rodovia BR 330, no sentido Jitaúna - Ipiaú, cá pras bandas do município de Aiquara, quando se atravessa a ponte às margens do Rio de Contas, a primeira visão que se tem é a entrada do Povoado de Palmeirinha. Por volta de 1900 a 1910 um movimento imigratório leva algumas famílias a adentrarem a região. Sr. Urbano conta como foi à chegada de seus pais em Palmeirinha, vindo de Nova Laje região de Santo Antônio de Jesus, buscando relembrar os contos de seu pai.

Naquela época aquilo ali, aquela região ali, era toda ela, mata do Estado [...] Naquele tempo, quando a gente arrumava as coisas e botava nas costas, que vinha e mudava de lugar, chamava "cacai". Botou o cacai nas costas e veio embora da Lage pra aí, de pés, chegando aí botando os pés dentro d'água, os pés inchados essa coisa toda. Mas ele disse o seguinte, quando chegou aí encontrou uma mataria linda, porque na 
verdade era um terreno de mão cheia, ainda é até hoje. Isso tem o quê? 100 anos? É 100 anos. Porque de 1910 pra dois mil e tanto, é 100 anos. Então, o velho meu pai me contava: Óia, meu filho! Quando eu cheguei aqui, que eu vi a mataria, uma mataria linda que tudo que se plantava, dava com muita abundância, aí eu disse, pronto! Vou arriar o meu cacai aqui e vou trabalhar na mata do Estado.

O termo "Mata do Estado", trás em si o histórico do processo colonizador português, onde a distribuição do título de propriedade da terra era determinada pelo sistema sesmarial, através das capitanias hereditárias, sistema que vigorou até por volta de 1822. Em 1850, é criada a Lei 601, conhecida como a Lei de Terras, que surge da necessidade de normatizar e estabelecer padrões para a distribuição e apropriação de terras.

A Lei no 601/1850, Lei de Terras - segundo Miranda (2011) - constituiu uma condição de anistia quanto às ocupações irregulares de terras advindas até a sua homologação: sesmarias ou concessões poderiam ser legitimadas, desde que comprovada à posse de terras cultivadas ou sua ocupação útil. O mesmo para a ocupação primária da terra - quando não se sujeitasse o título conferido pela Coroa - podia ser validada, anistiando assim a posse irregular sobre terras praticada no momento da entrada em vigor da Lei. As demais terras do Império seriam consideradas “terras devolutas”.

No mundo contemporâneo com a crise ambiental à espreita, é impensável uma mata/floresta como sendo "devoluta", isso levando em consideração apenas o contexto ecológico sustentável. Conceito que reforça o extrativismo colonial da época.

Somando a essa ponderação fatores sócio étnicos, cuja existência de povos indígenas de diferentes etnias, primeiros habitantes do território brasileiro, além da vinda de milhares de africanos escravizados. Aos indígenas, empregada à imagem de sujeito selvagem e aos africanos, negando-lhes a humanidade, onde a escravidão age "como instituição violenta que coisifica o negro" (CHAUÍ, 2000: p.27), a posse de terra para esses povos não eram efetivadas pela lei, "o discurso assimilacionista da igualdade racial era consoante com a ordem jurídica instalada” (BACELAR, 2002: p.51). Nessa perspectiva a terra devoluta, era a terra cujo proprietário não era reconhecido socialmente pelo Estado, logo, tomados todos num punhado só como os "não brancos". A ideia de cidadania estava diretamente relacionada à posse de terra

Num período bem próximo ao narrado pelo Sr. Urbano, a Sra. Ubaldina Lopes, conhecida como Tia Babá, nativa de Palmeirinha, numa passagem de suas lembranças 
conta da relação que seu pai mantinha com os índios, quando fazia longas viagens em tropas , "montado na anca do animal”, para compra e troca de mercadorias.

Porque pai foi dos índios, viu! Vinha comprar coisa cá...longe. Ele ia comprar. E os índio acompanhavam ele pela beira da estrada, ele disse: 'Óia, não me mete medo, não...quando eu vim...vou trazer fumo e coisa pra vocês'. Aí os índios acompanhavam ele até em Jaguaquara. Ele comprava ali...aqueles metros, e levava rolo de pano para fazer roupa e fumo. E levava o fumo e dava pros índio e dizia: 'Olha aqui!'. Os índios, no lugar em que ele botava o fumo, chegava no outro dia tinha uma caça...que os índios matavam e traziam pra ele...trazia aquelas caça, tatu, teiú...ele trazia pra casa, daí nós íamos tratar pra gente comer.

Uma relação estabelecida através de uma troca, cuja concessão da passagem pelo território indígena é condicionada ao oferecimento de um presente, nesse caso o fumo e o tecido. Quando ela se refere a "não me mete medo, não” nota-se que a relação era um tanto arredia, mesmo com a afirmação de que o "pai era dos índios". Uma relação de proximidade configurado pela troca, "aparentemente livre e gratuito, e no entanto obrigatório e interessado", tendo nesse tipo de fenômeno social, segundo Mauss (2003: p. 200-201), o envolvimento de dois sistemas de ideias importantes: a) "a natureza do vínculo jurídico criado pela transmissão de uma coisa”, que seria a obrigação de retribuir; b) "a natureza mesma da troca por dádivas, de tudo aquilo que chamamos prestações totais", pois aceitar algo ofertado por alguém é criar um vínculo com sua essência espiritual.

No início do século XX, a região que hoje é emancipado Aiquara, fazia parte das terras do distrito de Jequié, até então pertencentes ao município de Maracás. O professor Emerson Pinto de Araújo (1971), historiador e pesquisador da história de Jequié, destaca as atenções voltadas para essa região, desvelando a luz que permeavam as relações étnicas.

Como já foi dito, a antiga fazenda Jequié, outrora encravada no grande latifúndio 'Borda da Mata', começou a florescer a partir da sexta década do século passado. Vencidos os últimos redutos dos terríveis mongóios, desbaratados os quilombos do Sertão da Ressaca, a modesta propriedade situada na confluência dos rios Jequiezinho e das Contas, a meio caminho da mata e da caatinga (o que já era uma imensa vantagem, dada à facilidade de permuta de mercadorias das duas zonas), começou a servir de pouso das tropas e boiadas, oriundas do norte de Minas, que buscavam a Cidade do Salvador.[...] Diariamente chegavam à cidade 
centenas de burros, trazendo mercadorias que eram transportadas pela estrada de ferro. (ARAÚJO, 1971: p.157)

Não devemos perder de vista que o discurso de Araújo (1971), não era um pensamento especifico do autor, mais uma ideologia instituída por um grupo dominante "branco", "relutante inocente" quanto a sua mestiçagem. Onde os indígenas são adjetivados como "terríveis" e ainda, refere-se ao aniquilamento dos quilombos como "desbaratados". Na perspectiva retratada, os índios assumem o papel de inimigos terríveis que precisavam ser vencidos. E no viés dos movimentos emancipatório, em prol da abolição, as comunidades negras, representavam o medo, precisando ser sobrepujados. Ainda com o olhar do colonizador, vivendo a mudança do sistema escravocrata, para o pós-abolicionismo, período que Célia Maria Marinho de Azevedo (1987) reconhece como "tempo de transição".

Para isso era preciso que se forjasse uma população plenamente identificada com a idéia de pátria, de sociedade brasileira, não só em termos de limites geográficos como principalmente no sentido de uma ética nacional. Contudo, a percepção de uma explosiva heterogenia sócioracial destacava-se como um considerável entrave no pensamento daqueles que almejavam transformar o país recém-independente em nação. (AZEVEDO, 1987: p. 60)

Ao mesmo tempo em que é negado ao índio e ao africano seu pertencimento a formação da nacionalidade brasileira, atina-se para um movimento de apropriação da nacionalidade europeia, um processo de branqueamento, reforçado pelos projetos imigrantistas, que aconteceram em todo país. Segundo Bacelar (2002), a Lei de Terras juntamente com o fim do tráfico de escravos, foram fatores que impulsionaram a imigração estrangeira e Azevedo (1987) ressalta a inquietação dessas políticas com o propósito de tornar o Brasil um país homogêneo, anterior ao período da independência. 
Imagem 1 - A balsa e a canoa transporte utilizado para travessia do Rio de Contas. ${ }^{1}$

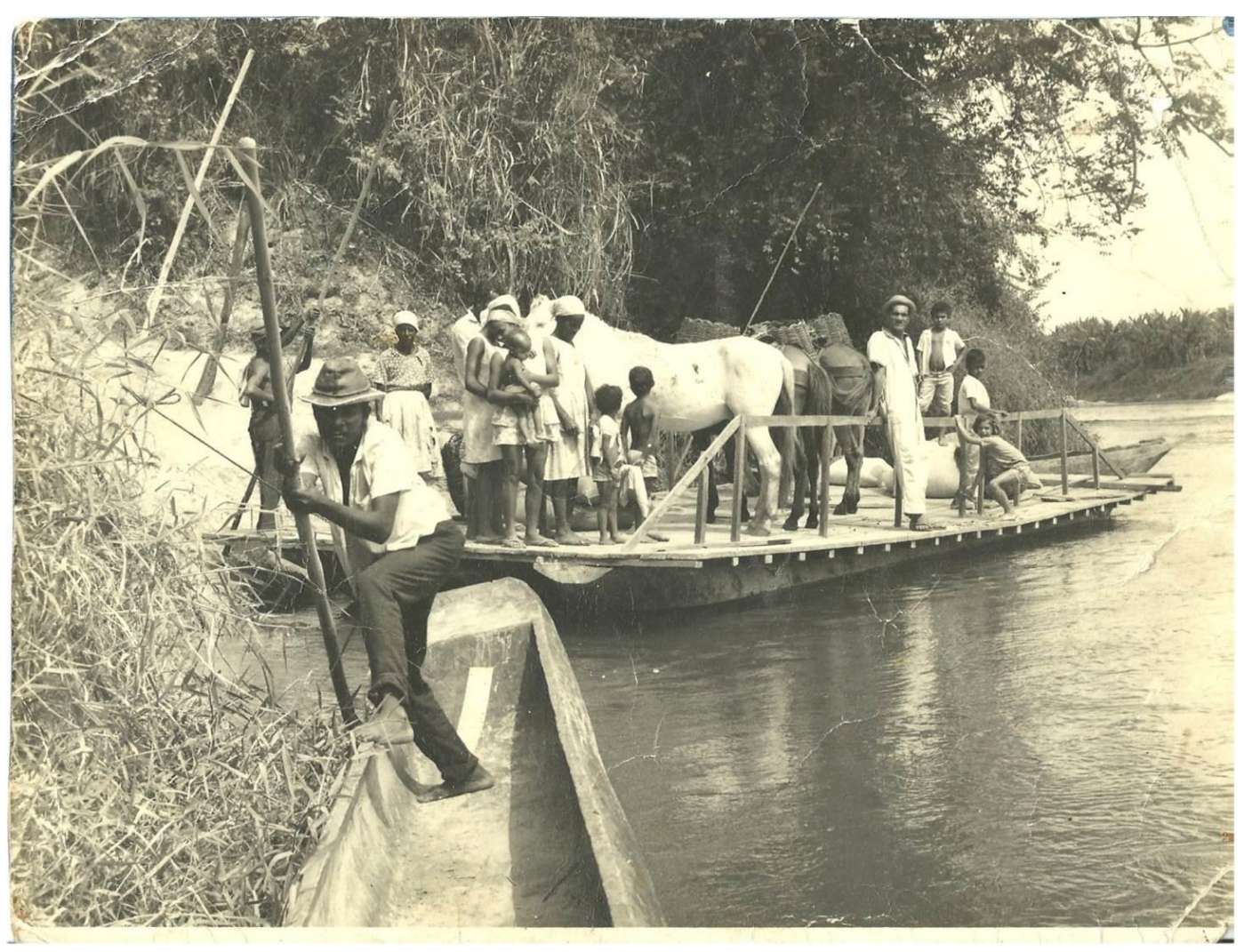

Na imagem registrada em Palmeirinha, as margens do Rio de Contas, entre 1930 a 1940 aproximadamente, podemos elencar aspectos característicos desta população, categorias étnicas, como as formas de transporte. Identificamos a canoa e a balsa, utilizados em translados aquáticos, demonstrando a forte relação com o rio, além da habilidade de navegação. Ressalta-se a prática de feitura artesanal da canoa, esculpida num tronco único, técnicas de construção sustentadas pela tradição oral, cujas manobras aquáticas são controladas com um remo. Além dos cavalos selados com balaios pendurados, usados para transportar cargas no lombo de animais, em curtas e longas distâncias. Os balaios são trançados de cipó, técnica creditada aos indígenas do Brasil. $\mathrm{Na}$ balsa, as mulheres com panos amarrados na cabeça. A imagem revela também aspectos relevantes sobre a população. Destaca-se a cor da pele escura. Há presença de negros e mestiços.

Em Palmeirinha, até o momento não podemos afirmar de onde originaram os negros presentes na região, se vindos do Recôncavo, ou do Litoral Sul, ou até mesmo

\footnotetext{
${ }^{1}$ Fonte: Acervo fotográfico pessoal da Sr. Maria Antonia, professora aposentada de Palmeirinha e filha do canoeiro Ziza.
} 
de Minas Gerais, apenas com um estudo mais aprofundado poderíamos supor a origem. O estado da Bahia até o ano de 1830 estima-se ter importado cerca de 1 milhão de negros para o trabalho escravo, do total de 4 milhões de africanos importados ao Brasil (Viana, 1988). Os africanos escravizados e seus descendentes participaram legitimamente na sociedade nacional, contudo desmerecido, em todo e qualquer empreendimento,

Nela se viu incorporado à força. Ajudou a construí-la e, nesse esforço, se desfez, mas, ao fim, só nela sabia viver, em razão de sua total desafricanização[...]. Calculo que no Brasil, no seu fazimento, gastou cerca de 12 milhões de negros, desgastados como a principal força de trabalho de tudo o que se produziu aqui e de tudo que aqui se edificou. (RIBEIRO, 1995: p.202-203.)

Contudo, a chegada do negro ao Brasil revela a violência histórica do tráfico africano, orquestrado pela "civilização" europeia, alimentando, e sendo alimentado, pelo capitalismo emergente, em busca de braços que movimentassem a produção, justificado pela hierarquização cultural, instituído num conceito biológico evolucionista de raça. A coisificação do negro nutre a perspectiva do negro como mera ferramenta de trabalho, negando-lhe a humanidade, e edificando aí as bases da relação dicotômica eurocêntrica entre o branco e não branco no Brasil. A humanidade do negro infringiria as convenções doutrinária cristã que trariam o caráter de pecado, a dilaceração dos “irmãos" não brancos, filhos do mesmo "Pai”. Costa (1986: p.92) ao tratar das violências sofridas pelos sujeitos na constituição de suas identidades, ressalta que a violência está integrada à disparidade de domínio, e que ela evoca a ruptura de uma convenção, pelo dominante que a conhece, mas que deliberadamente as transgride, abusando da força e com os elementos que possui, relacionando a violência ao abuso de poder.

Tratados como "coisas" o negro escravizado era comercializado, e sua força de trabalho era naquele período os braços que movimentavam a economia nacional. $\mathrm{O}$ processo abolicionista se articula a partir do discurso da humanização do negro, que até então era discutida na perspectiva das teorias evolucionista, num campo biológico, que subjugavam o negro a uma escala inferior na evolução humana. Schwarcz (2014: p.78), aponta a três proposições que norteavam a lógica das "raças humanas", admitindo a existência de uma hierarquização racial, cujo topo seria a raça pura (branco), cuja primeira hipótese é de que existia entre as raças humanas a mesma distância entre o cavalo e o asno; a segunda premissa associava que a mesma divisão estimada para a 
raça correspondia também à cultura; e por fim, que preponderava um determinismo étnico, que seria a universalização de traços físicos e comportamentais comum a todos os sujeitos de uma "raça” específica. Esses eram os fatores que moldavam o significado de ser negro no Brasil.

Africanos de diversas nações, com diferentes culturas, em alguns casos rivais por gerações, foram forçados pelas circunstâncias a se relacionarem. E na busca da reconstituição desse processo, amparado pela memória, ancestralidade e a tradição oral, a História da África pode ser associado a qualquer assunto relacionado ao Brasil, de forma, a História do Brasil ser um capítulo da História da África.

Tanto Munanga (2006), Bacelar (2002), Azevedo (1987), Schwarcz (2014) e Chauí (2000), retratam em suas obras como a diversidade racial era concebida como limitação para o desenvolvimento do país na perspectiva da classe dominante. Cuja pluralidade era hierarquizada tomando como padrão de superioridade o branco europeu.

Mais uma vez, a valorização do europeu como o tipo de trabalhador e cidadão ideal repousava sobre a idéia da inferioridade racial de grande parte da população brasileira. Um redator do jornal, possivelmente o próprio Taunay, não deixava margem a dúvidas quanto à superioridade racial do europeu, reconhecendo que o aproveitamento dos nacionais no mercado de trabalho livre atenderia a necessidades complementares, porém bem menos importantes do que aquelas destinadas ao imigrante. (AZEVEDO, 1987: p.85.)

A Bahia como o estado mais negro do país não queria mudanças no sistema escravista, uma vez que a economia baseava-se na atividade rural e por isso, a mão de obra escrava sustentava as grandes lavouras. Azevedo (1987) defende que o escurecimento da população assustava a elite branca, entretanto o medo e os esforços para o branqueamento eram ineficientes a mestiçagem. A busca por afirmar uma identidade nacional no Brasil deparava-se com o embate da diversidade cultural, vista como legado colonial. Tomando-se como premissa máxima a "nação" Brasil iniciada com o processo de colonização portuguesa.

A pluralidade racial nascida do processo colonial representava, na cabeça dessa elite, uma ameaça e um grande obstáculo no caminho da construção de uma nação que se pensava branca, daí por que a raça tornou-se o eixo do grande debate nacional que se travava a partir do fim do século XIX e que repercutiu até meados do século XX. Elabora- 
ções especulativas e ideológicas vestidas de cientificismo dos intelectuais e pensadores dessa época ajudariam hoje, se bem reinterpretadas, a compreender as dificuldades que os negros e seus descendentes mestiços encontram para construir uma identidade coletiva, politicamente mobilizadora. (MUNANGA, 2006: p.51)

Esta afirmação parte dos enlaces da mestiçagem, em que o Brasil se faz Brasil a partir do fluxo cultural com a Europa e África. Dito assim parece desmerecer os povos, as etnias as nações indígenas que aqui habitavam, já que "terra de índio" não tem nome, logo, precisava ser "batizada". Daí, tomando o Brasil como ideia anota-se o propósito da ideologia de "universalização", da necessidade de instituir um sistema cultural como único e verdadeiro. Num cenário como esse cuja supremacia branca define os modelos, Costa (1986: p.108) acredita que “o sujeito negro, possuído pelo ideal de embranquecimento, é forçado a querer destruir os sinais de cor do seu corpo e da sua prole".

A relação entre o branco e não branco, trás algumas vertentes que merecem atenção. Primeiro, a caracterização tomada pela cor, e o branco, adotado como referência primordial. Em segundo, a caracterização do ser branco passa pela aceitação de fazer parte do grupo branco, cujo ingresso vincula-se a cor da pele e origem - berço genuinamente branco - assim, o conjunto branco não leva em consideração nem a própria diversidade cultural do grupo, onde portugueses, espanhóis, holandeses, alemães, ingleses entre outras nacionalidades são tomados todos por uma só medida, o ser branco, e nesse lugar do ser branco as diferenças, sociais, políticas, étnicas, culturais, são apaziguadas. Em terceiro, a perspectiva do não branco, que seria o conjunto de todos que não foram aceitos como brancos, aqui, é mais forte a relação de pertencimento e reconhecimento, onde para ser não branco, não seria exatamente uma questão de "ser" e sim de "não ser", nesse caso, não ser branco.

A denominação "não branco", apesar de não valorizar a diversidade étnica, e promover distanciamento do que seria aceitável culturalmente pela Europa, reforçando a relação daninha civilizado/selvagem, segundo Munanga (2006) no processo identitário "vai permitir o desencadeamento de um processo de construção de sua identidade ou personalidade coletiva". Tomar diversos grupos étnicos vindo de África, a diversidade étnica indígena que já habitavam o país, e unificarem num só grupo limitados a um só lugar, território e a situação social, o lugar o do não branco, dentre 
outros fatores, motiva a confluência de elementos de fronteiras, confabulando em elemento que fortaleçam a identificação entre os grupos, e constituam elementos comuns as diversas culturas.

Essa identidade, que é sempre um processo e nunca um produto acabado, não será construída no vazio, pois seus constitutivos são escolhidos entre os elementos comuns aos membros do grupo: língua, história, território, cultura, religião, situação social, etc. Estes elementos não precisam estar concomitantemente reunidos para deflagrar o processo, pois as culturas em diáspora têm de contar apenas com aqueles que resistiram, ou que elas conquistaram em seus territórios. (MUNANGA, 2006: p. 14)

A intitulação de grupos como afro-americano, afro-brasileiro, afro-indígena, valorizam as relações com realce aos recortes, entretanto tende a dividir os grupos, alienando os processos de identidades. A mestiçagem hora tomada como mancha indelével a pureza da identidade nacional, hora vista como o estandarte para unificação da diversidade cultural, ainda tem muito a ser discutido.

Santana (2004: p.12-13) contextualiza bem o pensamento comum do período da colonização, quando diz que "o que se buscava para o africano era que o mesmo tivesse uma identidade cristã, embora lhe fosse negada a humanidade”. Esse pensamento justifica a busca de "recuperar culturalmente os povos considerados pagãos", estimulando o processo de cristianização.

(...) mesmo considerando o trabalho forçado e a violência padecida pelos índios, não se pode esquecer que o comércio de escravos teve como objeto os negros, e que era aos mesmos negada sua condição de humanos. Desde o início o europeu rejeitou a cultura do índio, mas não rejeitou sua natureza humana. (SANTANA, 2004: p.12)

A relação entre o "ser humano" estava diretamente relacionada a "ser cristão", a religiosidade sendo usada como meio de humanização. Daí, ideologias religiosas são incorporadas nos mais diversos discursos sociais. Diante a opressão voraz da qual estavam expostos, além de toda campanha dissimulada nos meios de comunicação em massa estruturando uma imagem negativa, suja e feia do "ser negro", a mestiçagem pode ser entendida como uma estratégia de sobrevivência dos sujeitos "não brancos". Para Munanga (2006: p.66), contextualiza o ideário de "ser branco" da época a status social, quando revela que "ter a pele clara, provir do 'sangue' europeu, não ter mescla 
com as raças 'inferiores', principalmente a negra, constituía, segundo as ideias da época, o distintivo da nobreza, da superioridade social e moral”.

O conceito de mestiçagem positivado cambaleia entre, valorizar a diversidade pontuando as diferenças, e unificar as diferenças violentando a diversidade. A identidade nacional não pode ser tomada como uma forma única, nem tão pouco como uma "forma de gelo", compostas por vários quadrados, desconsiderando a multipluralidade étnica com elemento de fluidez.

Palmeirinha é hoje um povoado onde vive uma comunidade de aproximadamente 500 habitantes, que se mantém basicamente das atividades rurais, entre a pecuária e o cultivo de cacau, hoje em dia atividade economicamente "fraca", em comparação aos áureos tempos no início do século XX, quando o cenário econômico baiano passava por processo de mudanças, reestruturando-se do impacto causado pelo período abolicionista, cuja libertação dos escravizados faz com que a cultura da cana de açúcar decaia, possibilitando a abertura de novos mercados.

Noelio Dantaslé Spinola (2004: p.92) em seus estudos sobre a História Econômica da Bahia, retrata a importância econômica que a cultura cacaueira representou para o sul da Bahia, na segunda década do século XX. A partir de 1920 o cacau assume a liderança na produção agrícola estadual, esse fator destaca o sul da Bahia, Ilhéus e Itabuna são responsáveis por mais de 60\% das exportações estaduais, embora as situações adversas como "os efeitos de danosas políticas do governo federal, da persistente tendência à deterioração do câmbio, das pragas dos cacauais e da imprevidência dos produtores em relação às oscilações dos preços no mercado externo”.

\section{O RIO}

Palmeirinha é um a comunidade agrícola ribeirinha. Antes das construções das barragens, desmatamentos da mata ciliar e assoreamentos, o Rio de Contas orientou durante algum tempo o escoamento das produções agrícolas levadas à Jequié, que por sua vez distribuía para a região sudoeste do país, por vias da estrada de ferro. É na localização do povoado que o Rio da Palmeirinha deságua no Rio de Contas.

Segundo Chiapetti e Chiapetti (2011: p.73), O rio com suas águas doces correntes atuam no imaginário, seja pela sustentabilidade da vida, "seja pela possibilidade de refletir, seja pela capacidade de fazer deslizar, seja pelo seu movimento, seja pela sua 
calmaria, seja pelo seu destino certo”. Exerce funções simbólicas. A água é matéria ao mesmo tempo imaginação.

A imaginação imita modelos exemplares - as Imagens -, reproduzindo-os, reatualizando-os, repetindo-os infinitamente. Ter imaginação é ver o mundo na sua totalidade; pois as Imagens têm o poder e a missão de mostra tudo o que permanece refratário ao conceito. (ELIADE, 1991: p.16)

A fluidez do rio nos licencia deslizar por sua superfície em navegação, transitar, escoar, viajar. Um rio é vivido, por quem se permite fluir em seus movimentos correntes. Na firmeza de suas margens mulheres choram por seus filhos levados pelo rio, cantam enquanto quaram suas roupas. A mesma margem que separa, também é unida pelo rio.

O Rio de Contas é o principal rio da Bacia Rio de Contas, que leva o seu nome, que tem como principais afluentes o Rio Brumado, Rio do Antônio, Rio Gongogi, Rio Jequiezinho, Rio Gavião, Rio Sincorá e Rio Jacaré. A nascente do Rio de Contas é localizada na Serra da Tromba, entre o município de Piatã e Rio de Contas, da Chapada Diamantina. O rio passa por vários cenários, antes de enfim desaguar no mar - passeia pela Chapada Diamantina, em seguida prestigia a caatinga, refresca a zona da mata e por fim deságua nas areias do litoral baiano. O Rio de Contas cenário de capítulos históricos por onde passa. Algumas cidades, estradas, negociações, associações, são estabelecidos a partir do curso de suas águas.

Não há uma convenção quanto ao nome do rio, se RIO DE CONTAS ou RIO DAS CONTAS. Adotamos Rio de Contas por ser a forma reconhecida em Palmeirinha. A origem de seu nome ainda bastante estudada especula-se que os índios dessa região o titulavam de Jussiape, chegou a ser chamado pelos espanhóis de Rio São Julião, e também de Rio Santo Agostinho. Segundo o historiador Borges de Barros, o nome faz alusão à existência de pedras redondas e azuladas, parecidas com "contas", que se espalhavam pelo leito do rio. Já Araújo (1971) salienta que a explicação mais plausível quanto ao nome é de Aristides Milton²: nas proximidades da atual cidade de Jussiape, na Chapada Diamantina, durante a mineração em épocas pré-fixadas, encontravam-se

\footnotetext{
${ }^{2}$ Aristides Milton da Silveira nascido em 6 de maio de 1894 na cidade de Cachoeira, Bahia, reconhecido no estado por suas atividades na política baiana. Engenheiro, atuou como Chefe da construção da Estrada de Ferro de NazaréBA, diretor de Obras e Jardim da Prefeitura de Salvador. Foi diretor do Patrimônio Municipal de Salvador e professor de Geofísica e Cosmografia no Ginásio da Bahia.
} 
mineradores e cobradores do "quinto de ouro" para acertar contas, daí a denominação RIO DE CONTAS.

O rio, numa concepção simbólica, permite também o trânsito cultural, uma vez que ele é o principal vetor de acesso às trocas. Nas idas e vindas das trocas mercantis, elementos de subjetividade são agregados, como também são doados constituindo os vínculos, alianças e relações que são, sobretudo, trocas simbólicas. Nas comunidades ribeirinhas os movimentos do rio orientam as relações: com o próprio rio, e consequentemente com as pessoas. Para a população de Palmeirinha houve duas enchentes marcantes do Rio de Contas uma em 1914 e outra em 1945. Conta Sr. Urbano que "a enchente de 14 " foi vivida pelo seu pai, aconteceu no ano de seu nascimento, mesmo assim faz referencias como tendo sido uma "enchente braba", já a de 1945 ele se recorda.

Ziza era minha pessoa. Quando chegava ali no rio, cadê o rio? Não podia passar, eu ia atrás de Ziza. Ziza meu amigo eu quero ir pro outro lado. Aí ele remando no leito passava, subia passava quando dobrava. Vixe... minha Nossa Senhora! [...]Nessa época, que eu vinha, eu era menino. Tempo que Ziza atravessava...era por volta de 1940, por aí...viu. 1940. Não. Eu nasci em 26, mais 14. É isso mesmo, 1940...45. Até que em 45 teve uma enchente desgraçada no Rio das Contas de novo. Era nessa época, que só atravessava o rio ali de canoa. 
Imagem 2 - O canoeiro Ziza fazendo a travessia do Rio de Contas. ${ }^{3}$

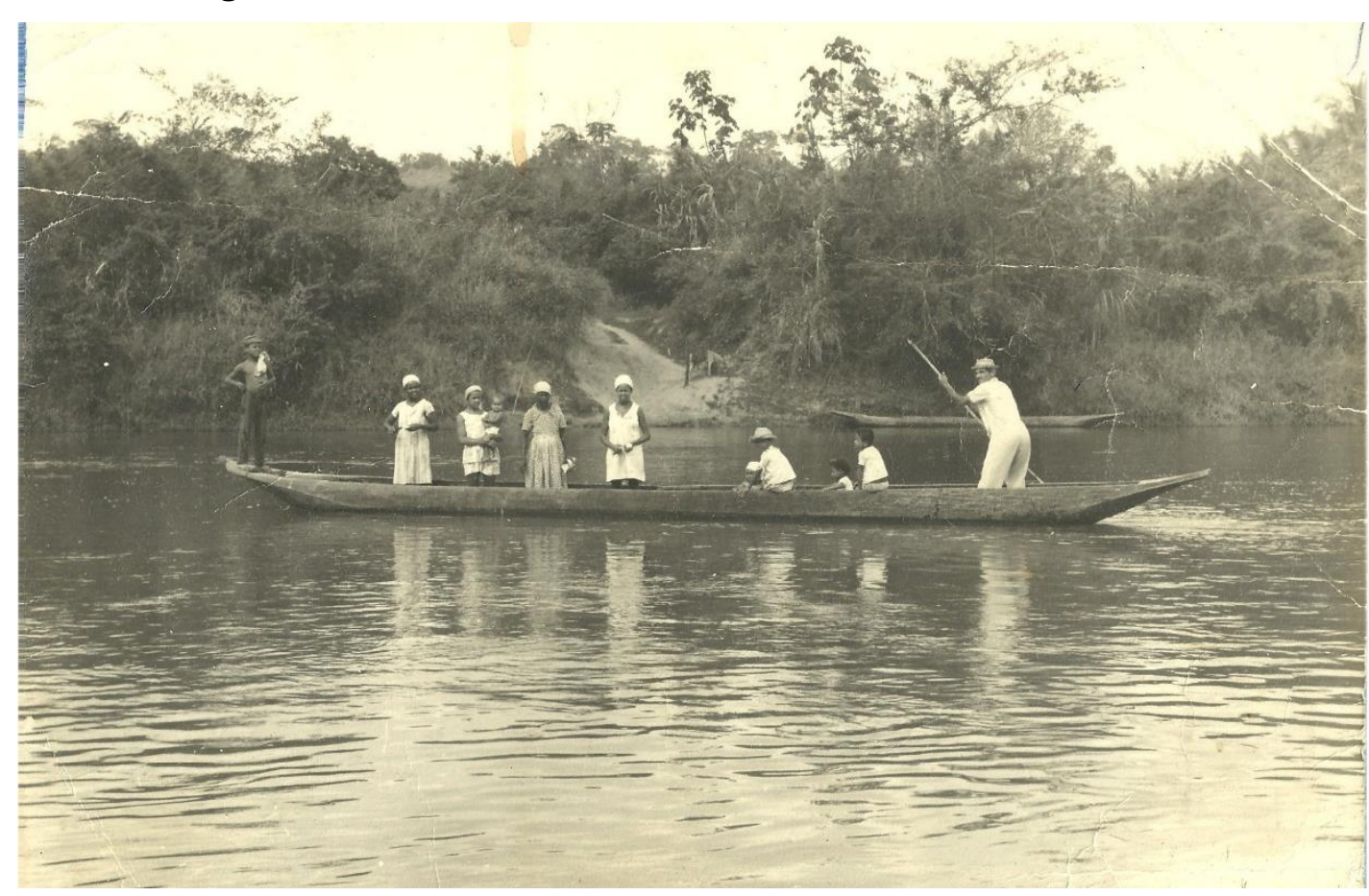

O Rio de Contas não é o único rio relevante para o Povoado de Palmeirinha. Tem o Rio Preguiça diretamente ligado à origem do município de Aiquara. Entretanto, o Rio da Palmeirinha tem maior evidência devido à proximidade com o povoado.

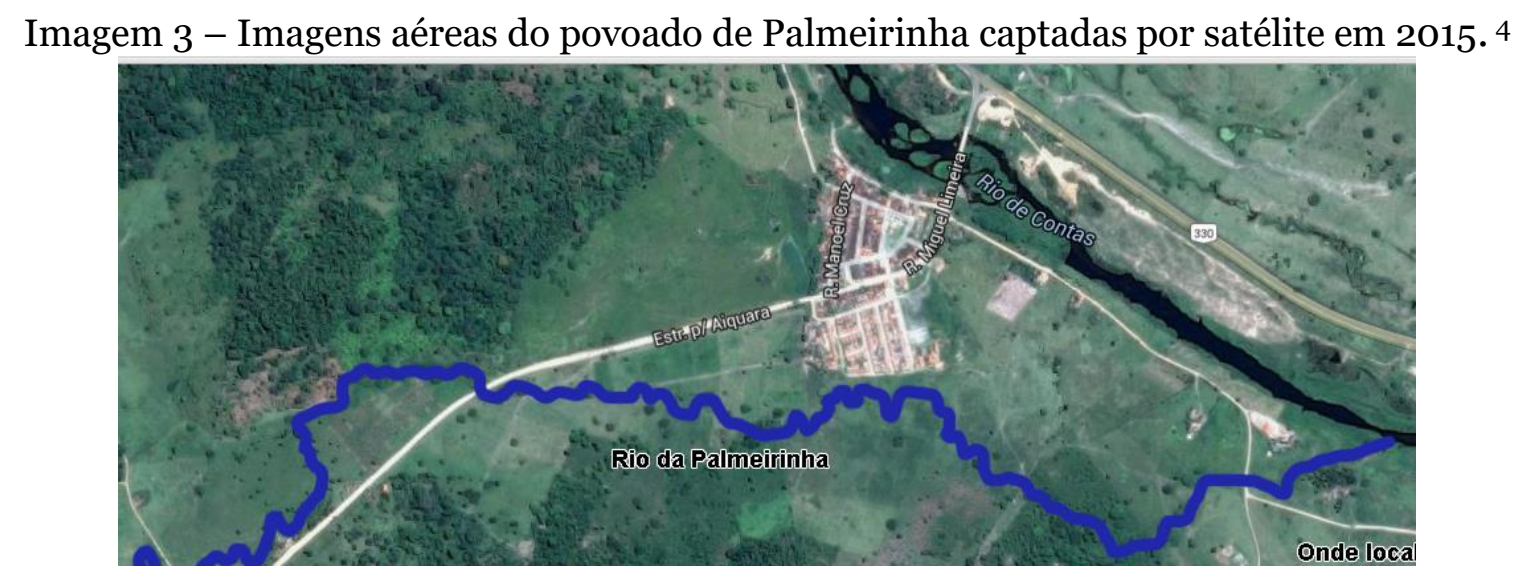

O Rio da Palmeirinha é citado no depoimento do Sr. Urbano, segundo ele, naqueles tempos o rio era perene, hoje é um rio sazonal, só corre água nos períodos de

\footnotetext{
${ }^{3}$ Fonte: Acervo fotográfico pessoal da Sr. Maria Antonia, professora aposentada de Palmeirinha e filha do canoeiro Ziza.

4 Fonte: Google Map. Disponível em: <https://www.google.com.br/maps/place/Palmeirinha,+Aiquara++BA/@ 14.0420378,39.8305946,1326m/data=!3m1!1e3!4m2!3m1!1s0x73f52ba0a1b5c2d:0x2c802cc36a3 b0f1b> Acessado em 16/10/2015.
} 
muita chuva. Durante toda a fala dele é possível notar o uso do rio como marcador de localização, em alguns momentos de sua fala o rio e o povoado se enredam.

A gente morava praticamente no meio da estrada entre Dona Genoveva e Aiquara, e aí a nossa ligação era ou com Aiquara, o Arraiá da Conceição ou com a Palmeirinha chamada, que é ali que era legítima Palmeirinha. Você vai pra Palmeirinha? Eu vou. Pra onde? Pra casa de Dona Genoveva. Era ali. Chegava ali onde tem a ponte a gente descia lá adiante tinha um sobradinho alto, uma casa alta, lá era a casa de Dona Genoveva.

A composição do povoado é articulada aos trajetos dos Rios de Contas e da Palmeirinha, o local para as construções são escolhidos a partir dos movimentos de cheia dos rios. Muitas atividades de subsistência e rotina da comunidade dependem do rio. A água como elemento natural essencial a vida traz em si muitos significados conjecturados entre o material e o imaterial. O Rio de Contas que inspira poemas, também é o lugar onde transita o mágico, o ilógico.

Devido às especificidades dos depoimentos analisados, Sr. Urbano desenha o rio sob um aspecto histórico geográfico, enquanto Tia Babá narra as subjetividades, do rio como elemento simbólico, em alguns momentos nem parecem tratar do mesmo lugar. Nas narrativas feitas por Tia Babá o rio é um lugar mítico, onde pedras cantam e encontrava-se enterrado "carrote" de ouro e prata. O rio deriva mito.

Tinha uma pedra medonha, e eu ia lavar roupa... pro riachão medonho lavar roupa. Lá em cima a gente pegava aquela roupa, aí depois que tirava o sujo daquela água... pegava aquela roupa estendia assim... pra... pra arejar um pouco, pra poder torcer, pra roupa ficar alva. Naquilo que acabei de torcer a roupa, que eu tava pra vim pra casa... a pedra...bem a pedra tava cantando...uma cantiga: 'Oh, lelê o lalá! Oh, lelê o lalá! Eu quero ver os cavaco avoar, Eu quero ver os cavaco avoar...' batia de dentro da pedra assim! Aquele samba danado. Quem disse que nunca mais eu cantei isso? Ave Maria...! Tomei um medo danado. 'Madrinha Laura!' contei o causo, madrinha Laura: 'Deixa de ser medrosa'. Eu vou me dizer uma verdade...nunca mais eu vou lá sozinha, não. E não cantei mais isso. Fiquei com medo...

$[\ldots]$

E daquilo...oxen...como eu tô dizendo...eu ia levar uma carga de animal, que não tinha estrada antes. Não tinha estrada em lugar nenhum. Ia assim, pela beira do rio. Rio Branco, quando chegou cá dentro assim, parou. Pra levar aqui pro do lado de Jequié. O povo bateu, assim...páa...o pé no negócio assim. Ele olhou...era um arco...aquele negócio assim de botar cachaça? Carrote...Cheio de prata e ouro... Ouro, 
que comprou uma fazenda. Tinha um véi, o velho Caboré. O velho Caboré, pela estrada de cá, assim... pra passar em Rio Branco. Ah, meu Deus do céu! Aquilo ali saí pelo Rio Branco, beirando o Rio de Contas, pra sair. Era uma luta medonha!

"Medonho" o Rio de Contas mete medo mesmo, pra quem não sabe respeitá-lo, mas também corre calmo em águas tranquilas. São atribuídos ao rio características e sentimentos. Um rio que nasce quando brota na flor de uma nascente, também morre quanto deságua no mar. O rio simboliza a vida e a morte. Duas faces do mesmo lugar. O rio implica transformação.

os rios são construtores de mundos sociais e aglutinam em torno de si uma boa quantidade de representações como "lugar de significação" que são. Servem de baliza ou marco quase míticos para estratégias socioculturais. Os rios significam muito mais do que simples suportes físicos ou acidentes geográficos traçados nos mapas ou, ainda, recursos da natureza. Eles são paisagens...são lugares em que as pessoas se abrem aos mistérios da natureza, ao patrimônio simbólico, possibilitando a interpretação da criação cultural, um encontro das pessoas. (CHIAPETTI; CHIAPETTI, 2011: p.75-76)

O Rio de Contas é um lugar em movimento, uma imagem em movimento. Cujos significados são tomados da relação entre a água, a terra e as pessoas.

\section{Desaguando no mar...}

A etnicidade do povo brasileiro vem sendo amplamente discutida no objetivo de projetar as relações étnicas que resultaram a formação deste país. Simplificar a formação a partir de três grandes grupos étnicos: brancos, negros e índios. Fator que remete a ideia induzida de isolamento de cada um desses grupos.

Devido à amplitude e especificidades territoriais, dentre outros fatores subjetivos, as relações étnicas instituídas pelos povos brasileiros, se deram de formas peculiares ocasionando diversidades culturais, muitas vezes numa mesma localidade. Isso nos revela que a diversidade cultural está além da composição étnica de um grupo.

As construções simbólicas acontecem num campo de interação, onde são estruturadas sob contexto interétnico e estabelecidos das negociações de valores e significados. No campo de negociação preponderam as relações de poder, que atuam de formas significativas na cultura. A memória também é categoria acionada, e por vias dela, elementos outros são acessados nas delimitações das fronteiras. Ela tem a mesma liberdade de um rio, que desenha seus caminhos, estabelece seus movimentos e conflui livre no tempo. 


\section{REFERÊNCIAS BIBLIOGRÁFICAS}

ARAÚJO, Émerson Pinto de. A História de Jequié. Salvador: EGB Editora, 1971.

AZEVEDO, Celia M.M. Onda negra, medo branco: o negro no imaginário das elites do século XIX. São Paulo: Annablume, 1987.

BACELAR, Jeferson. A hierarquia das raças. São Paulo: Pallas, 2002.

CHAUÍ, M. Brasil: mito fundador e sociedade autoritária. São Paulo: Ed. Fundação Perseu Abramo, 2000.

CHIAPETTI, Rita Jaqueline Nogueira; CHIAPETTI, Jorge. A água e os rios: imagens e imaginário da natureza. Geograficidade. V.01, n.01, Inverno 2011, p.71-90.

COSTA, Jurandir Freire. Violência e psicanálise. Rio de Janeiro: Edições Graal, 1986.

ELIADE, Mircea. Imagens e Símbolos. São Paulo: Martins Fontes, 1991.

HALBWACHS, Maurice. A memória coletiva. São Paulo: Vértice, 1990.

MAUSS, Marcel. Sociologia e antropologia. São Paulo: Cosac \& Naify, 2003.

MIRANDA, Newton Rodrigues. Breve histórico da questão das terras devolutas no Brasil e dos instrumentos legais de posse sobre esses bens. Revista do CAAP, Belo Horizonte, n. 2, V. XVII, 2011, p. 153-176.

MUNANGA, Kabengele. Rediscutindo a mestiçagem no Brasil: identidade nacional versus identidade negra. Belo Horizonte: Autêntica, 2006.

POUTIGNAT, Philippe e STREIFF-FENART, Jocelyne. Teorias da etnicidade. São Paulo: Ed. UNESP, 2011.

RIBEIRO, Darcy. O povo brasileiro. São Paulo: Companhia das Letras, 1995.

SANTANA, Marise de. O Legado Ancestral Africano na Diáspora e o Trabalho do Docente: desafricanizando para cristianizar. Tese de Doutorado. PUC- SP, 2004.

SCHWARCZ, L.M.. O espetáculo das raças. São Paulo: Companhia das Letras, 2014. 
SODRÉ, Muniz. A verdade seduzida: por um conceito de cultura no Brasil. Rio de Janeiro: DP\&A, 2005.

SPINOLA, N. D. A economia baiana: os condicionantes da dependência. Revista de Desenvolvimento Econômico, Salvador, v. 6, n. 10, 2004, p. 88-99.

THOMPSON, John B.. Ideologia e Cultura Moderna: Teoria Social crítica na era dos meios de comunicação em massa. Rio de Janeiro: Vozes, 2011.

VIANA FILHO, Luiz. O negro na Bahia. Rio de Janeiro: J. Olympio, 1988.

Emily Alves Cruz Moy: Autora. Mestranda em Relações Étnicas e Contemporaneidade pelo Programa de Pós Graduação em Relações Étnicas da Universidade Estadual do Sudoeste da Bahia e bacharel em Administração e especialista em Antropologia com ênfase em cultura Afro-brasileira.

Flavia Querino da Silva: Coautora. Mestranda em Relações Étnicas e Contemporaneidade pelo Programa de Pós-Graduação em Relações Étnicas da Universidade Estadual do Sudoeste da Bahia - bolsista pelo financiamento da Coordenação de Aperfeiçoamento de Pessoal - CAPES. Graduada em Pedagogia (UNIME - Itabuna) e especialista em Psicopedagogia (ISEO - Itabuna).

Ana Angélica Leal Barbosa: Orientadora. Doutora em Ciências Biológicas pela UFPR. Professora Plena do Departamento de Ciências Biológicas da Universidade Estadual do Sudoeste da Bahia, campus de Jequié.

Artigo recebido para publicação em: julho de 2016

Artigo aprovado para publicação em: setembro de 2016 


\section{Como citar:}

MOY, Emily Alves Cruz; SILVA, Flavia Querino da; BARBOSA, Ana Angélica Leal. Em meio a chegança, cadê o rio? A etnicidade à margem do lugar. Revista Transversos. "Dossiê: História Pública: Escritas Contemporâneas de História". Rio de Janeiro, Vol. 07, nº. 07, pp. 134-153, Ano 03. set. 2016. Disponível em: <http://www.epublicacoes.uerj.br/index.php/transversos>. ISSN 2179-7528. DOI: 10.12957/transversos.2016.23593.

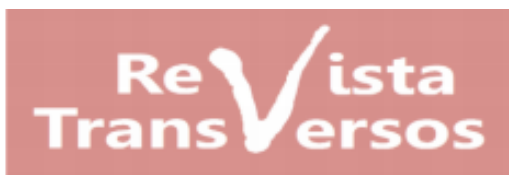

